\title{
Ulcerations due to methotrexate toxicity in a psoriasis patient ${ }^{*}$
}

\author{
Claudia Fernanda Dias Souza ${ }^{1}$ \\ Talita Fonseca Medeiros da Silva ${ }^{1}$ \\ Leonardo Pereira Quintella ${ }^{1,2}$ \\ João Carlos Regazzi Avelleira ${ }^{1}$
}

\author{
Olga Milena Zarco Suarez ${ }^{1}$ \\ Ana Carolina Lourenço Araújo Gorenstein ${ }^{1}$
}

DOI: http:/ / dx.doi.org/10.1590/abd1806-4841.20163960

\begin{abstract}
Methotrexate is one of the most used drugs in the treatment of psoriasis with indication of systemic therapy. Cutaneous and mucous side effects are described by pharmacological characteristics of the drug itself or due to overdose. We report the case of a patient with ulcerations in oral mucosa and psoriatic plaques after incorrect use of Methotrexate. Prescribed in a weekly dose, it was used continuously for 10 days and without simultaneous intake of folic acid. It is important to ensure correct comprehension of the prescription.
\end{abstract}

Keywords: Methotrexate; Psoriasis; Therapeutics; Toxicity

\section{INTRODUCTION}

Methotrexate (MTX) was introduced as antipsoriatic agent in 1951 and approved by FDA (Food and Drug Administration) with this indication in 1972. Structurally similar to folic acid, MTX is irreversibly linked to dihydrofolate reductase, exerting antiproliferative activity. It induces apoptosis and increases the concentration of adenosine, resulting also in anti-inflammatory and immunoregulation action. ${ }^{1}$

Psoriasis is a frequent dermatosis that may progress to severe forms that require systemic medication. ${ }^{2}$ In these cases, MTX is one of the most used drugs, due to its efficiency, safety (in prescribed doses) and low cost. However, overdose of MTX may cause important cutaneous, oral mucosa and systemic side effects.

The most common skin/mucosa alterations related to its toxicity are ulcerations on the oral mucosa, while reports of such alterations in preexisting psoriatic lesions or even on healthy skin are rare. ${ }^{3}$

\section{CASE REPORT}

A female patient, 58 years old, of mixed race, diagnosed with psoriasis 3 years before presented generalized lesions in the form of plaques and with poor response to topical treatment. The PASI (Psoriasis Area Severity Index) test had a result of 10.6. MTX was prescribed in a weekly dose of $10 \mathrm{mg}$ orally, accompanied by $5 \mathrm{mg}$ of folic acid 3 times a week. Ten days later she returned with intense dysphagia for solids and liquids, diarrhea and myalgia. She was dysphonic, with multiple erosions on the oral mucosa, hard and soft palate and ulcerations located mainly on the periphery of preexisting plaque psoriasis (Figures 1, 2 and 3). The histopathological examination revealed an ulcerated area covered by regenerating exudate and epithelium, ectasia in proliferated vessels and neutrophils at the bottom of the lesion (Figure 4). After denying irregular use of medication at first, the patient then admitted having ingested $10 \mathrm{mg}$ of MTX daily and that she had not used folic acid as originally

Received on 18.08.2014.

Approved by the Advisory Board and accepted for publication on 03.12.2014.

Work carried out at the Instituto de Dermatologia Professor Rubem David Azulay da Santa Casa da Misericórdia do Rio de Janeiro (IDPRDA/SCMRJ) - Rio de Janeiro (RJ), Brazil.

Financial Support: None.

Conflict of Interest: None.

Instituto de Dermatologia Professor Rubem David Azulay da Santa Casa da Misericórdia do Rio de Janeiro (IDPRDA/SCMRJ) - Rio de Janeiro (RJ), Brazil. Fundação Oswaldo Cruz (FIOCRUZ) - Rio de Janeiro (RJ), Brazil.

(C)2016 by Anais Brasileiros de Dermatologia 


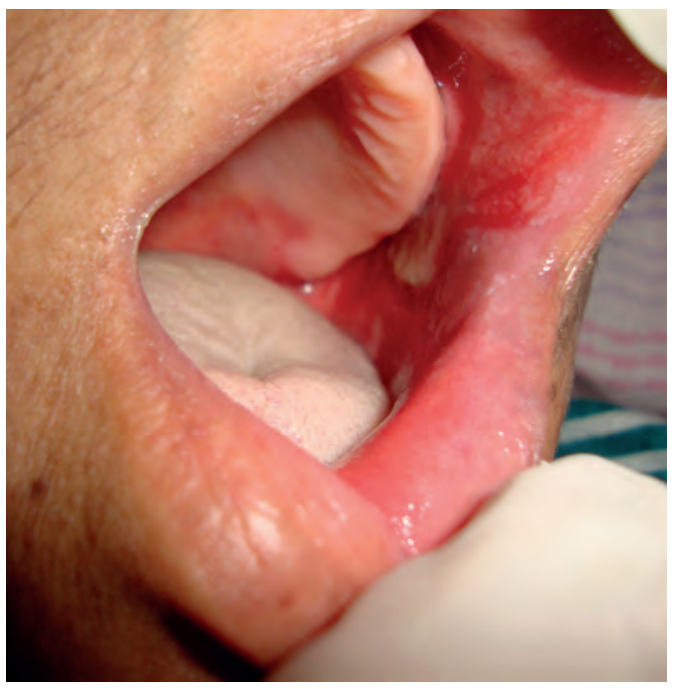

Figure 1 : Ulcerated lesion on oral mucosa

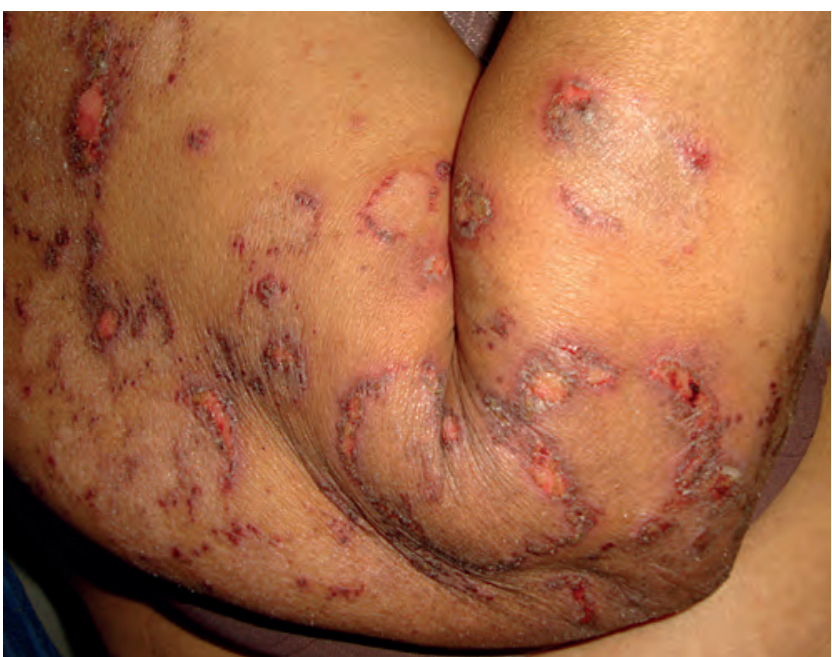

FIGURE 2 : Ulcerated areas in the a periphery of psoriatic plaques on upper limbs

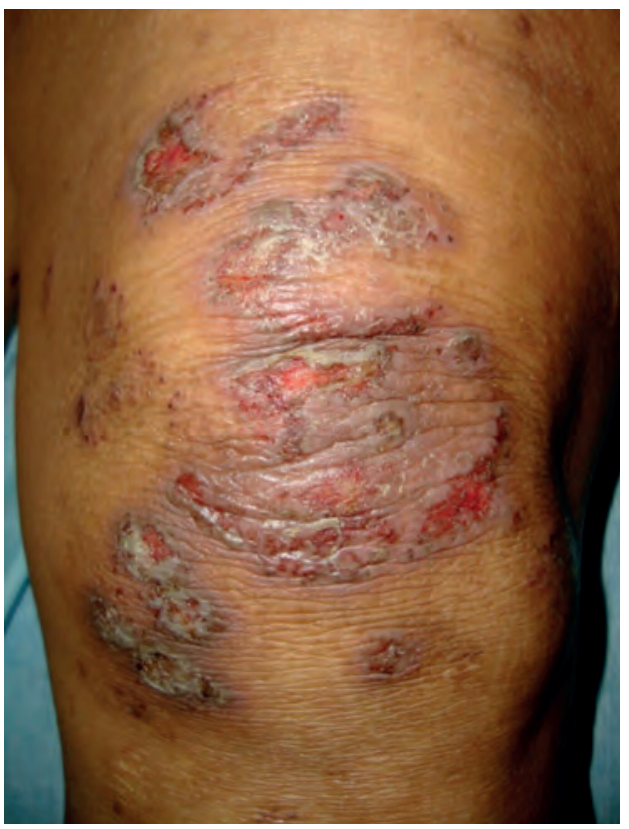

Figure 3 :

In closer detail, on left knee

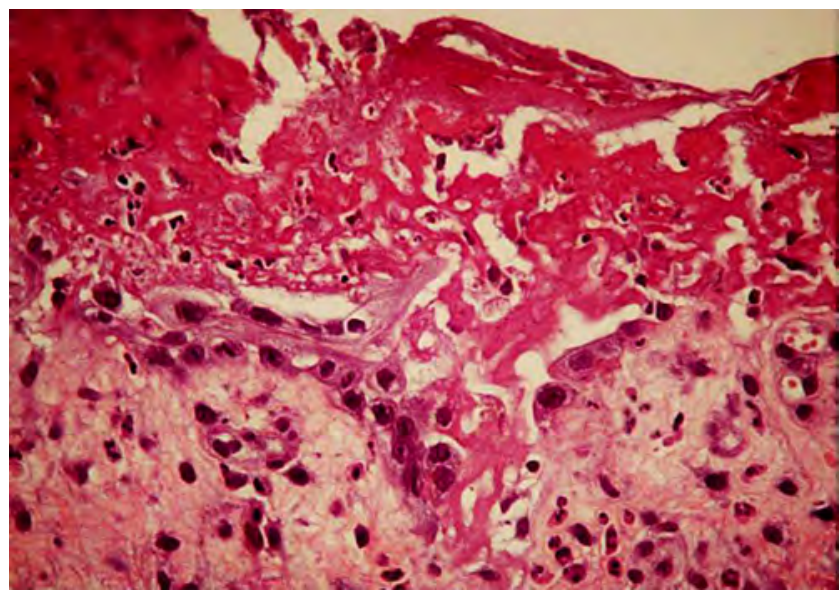

Figure 4 : Histopathology: Ulcerated area covered by exudate and regenerating epithelium. Proliferating vessels and neutrophils

recommended. She was hospitalized for evaluation of possible hematological and hepatic alterations and started receiving folinic acid $25 \mathrm{mg}$ / day intravenously.

The laboratory tests revealed leukopenia $\left(2.780 \mathrm{mil} / \mathrm{mm}^{3}\right)$ with hypersegmentation of neutrophils, decrease in total red blood cells, hematocrits and hemoglobin $(3.860 .000 \mathrm{u} / \mathrm{l}, \mathrm{HT}: 31.7 \%, \mathrm{Hb}: 10 \mathrm{~g} / \mathrm{dl})$ with absence of alterations in liver and kidney function. The patient progressed with rapid improvement and was discharged on the $8^{\text {th }}$ day of hospitalization. Thirty days later, follow-up showed complete reepithelization of lesions. The tests demonstrated normalization of leukocytes $\left(8.600 \mathrm{mil} / \mathrm{mm}^{3}\right)$ and slower recuperation of the red series (HT: $31.9 \%, \mathrm{Hb}: 10.1 \mathrm{~g} /$ dl). After being oriented again, the patient continued to use MTX, keeping the disease under control (PASI: 2.4) for 18 months of follow-up.

\section{DISCUSSION}

Methotrexate is a relatively safe drug in the dosage used in dermatology (7.5 $\mathrm{mg}$ to $25 \mathrm{mg}$ / week), with side effects and toxicity associated with idiosyncratic or dose-dependent mechanisms. The latter will occur mainly in cells that proliferate faster, like hematopoietic bone marrow cells, epithelial gastrointestinal tube and epidermal cells. As MTX is excreted by the kidneys and circulates in the blood flow conjugated with albumin, its administration to nephropathic patients or those with hypoalbuminemia should be done carefully or avoided. Furthermore, drug interaction (drugs that diminish renal excretion of MTX, that inhibit folate synthesis, or that decrease MTX binding to proteins) and errors in administration of the drug may trigger adverse effects through the increased drug level in the body. 
On the skin, the adverse affects are more rare. Not related to the methotrexate dose have been described: erythematous eruptions, blisters, toxic epidermal necrolysis, exacerbation of photosensitivity reactions, purpuric lesions due to vasculitis, hives and formation of nodules that may involve internal organs also, first reported in rheumatoid arthritis and later found in psoriasis and psoriatic arthritis. ${ }^{3-6}$

Cutaneous manifestations in patients with MTX dose-dependent psoriasis are more frequent due to acute intoxication. Ulcerations and ulcerative processes are observed on oral mucosa (more precocious), on psoriatic plaques, in other preexisting dermatoses or, more rarely, on healthy skin. ${ }^{3}$ They may be similar to a "flare-up" of psoriasis or to pustular psoriasis. $3,7,8$

Pearce and Wilson ${ }^{6}$ reviewed 47 cases in the period of 1951 to 1996 and found simultaneous use of non-hormonal anti-inflammatories and advanced age as risk factors. Many of these cases occurred in the first weeks after introduction of MTX or reintroduction of medication in patients with relapsing disease, suggesting the hypothesis of higher susceptibility to MTX of phase $S$ cells, that are found in larger numbers when there is acceleration of the epidermal turn over. $3,6-8$

The histopathological study of eroded cutaneous lesions shows a microscopic image similar to that observed after intradermal administration of the drug, suggesting that the reaction is caused by a direct cytotoxic effect. ${ }^{9}$ Therefore, the alterations observed would be derived from inhibition of keratinocytes by direct MTX toxicity, leading to epidermal necrosis.

In case of acute intoxication by MTX, skin signs and symptoms are a toxicity alert sign and may precede more serious hematologic alterations. The treatment is made with immediate suspension of the drug and administration of parenteral folinic acid in the dose of $10 \mathrm{mg} / \mathrm{m}^{2}$ of body surface; the earlier the treatment, the higher the success rate, mainly regarding the attempt to avoid or interrupt myelosuppressive effects. ${ }^{7}$ As regards skin lesions, reepithelization takes place between 1 and 2 weeks after interruption of medication and beginning of the new treatment. ${ }^{10}$

Methotrexate is an option of great therapeutic value for psoriasis, and its use should be well guided by the physician. The patient should be totally aware of the risks and side effects. More safety is achieved by means of a rigorous selection of patients (considering absolute and relative contraindications) and periodical clinical-laboratorial follow-up. In case of elderly patients or those with cognitive difficulties it is of fundamental importance for a companion to be present to ensure more safety to the offered treatment.]

\section{REFERENCES}

1. Alencar M.S, Avelleira JC. Metotrexate. In: Consenso Brasileiro de Psoríase 2012 guias de avaliação e tratamento Sociedade Brasileira de Dermatologia. 2 ed. Rio de Janeiro: Sociedade Brasileira de Dermatologia; 2012. 67-73p.

2. Ataíde DST, Esmanhoto LDK, Helmer KA, Guerra IRC, Guimarãesn CCG, Moritz S. Ulceração das placas psoriáticas - efeito adverso do metotrexate em altas doses no tratamento da psoríase: relato de três casos. An Bras Dermatol 2003;78:74953.

3. Kerstens PJ, Boerbooms AM, Jeurissen ME, Fast JH, Assmann KJ, van de Putte LB. Accelerated nodulosis during low dose methotrexate therapy for rheumatoid arthritis. An analysis of ten cases. J Rheumatol. 1992;19:867-71.

4. Lebwohl M, Ting PT and Koo JYM. Psoriasis treatment: traditional therapy. Ann Rheum Dis. 2005;64:iï3-6.

5. Lee HJ, Hong SK, Seo JK, Lee D, Sung HS. A Case of Cutaneous Side Effect of Methotrexate Mimicking Behçet's Disease. Ann Dermatol. 2011;23:412-4.

6. Pearce HP, Wilson BB. Erosion of psoriatic plaques: An early sign of methotrexate toxicity. J Am Acad Dermatol. 1996;35:835-8.

7. KishanKumar A, AmiyaKumar N, DevinderMohan T. Methotrexate toxicity presenting as ulceration of psoriatic plaques: A report of two cases. Indian $\mathrm{J}$ Dermatol Venereol Leprol. 2008;74:481-4.

8. Truchuelo T, Alcántara J, Moreno C, Vano-Galván S, Jaén P. Focal skin toxicity related to methotrexate sparing psoriatic plaques. Dermatol Online J. 2010;16:16.
9. López AA. Toxicidad aguda por metotrexate en psoriasis. Gac Méd Méx. 1999; 135:513-6

10. Fridlington JL, Tripple JW, Reichenberg JS, Hall CS, Diven DG. Acute methotrexate toxicity seen as plaque psoriasis ulceration and necrosis: A diagnostic clue. Dermatol Online J. 2011;17:2.

MAILING ADDRESS:

Claudia Fernanda Dias Souza

R. Santa Luzia, 206

Centro

20020-020 - Rio de Janeiro - RJ

Brazil

E-mail: cfdsouza.rj@gmail.com

How to cite this article: Souza CFD, Suarez OMZ, Silva TFM, Gorenstein ACLA, Quintella LP, Avelleira JCR. Ulcerations due to methotrexate toxicity in a psoriasis patient. An Bras Dermatol. 2016;91(3):375-7. 